\title{
SELF ESTEEM OF CHILDREN WITH SPECIFIC SPEECH AND LANGUAGE DIFFICULTIES
}

\author{
Geoff Lindsay $^{1}$, Julie Dockrell ${ }^{2}$, \\ Becky Letchford $^{2}$ and Clare Mackie ${ }^{1}$
}

Address for Correspondence:

Professor Geoff Lindsay

Director

CEDAR

University of Warwick

Coventry CV4 7AL

${ }^{1}$ Centre for Educational Development, Appraisal and Research, University of Warwick

${ }^{2}$ Psychology and Child Development, Institute of Education, University of London 


\section{$\underline{\text { Abstract }}$}

This study examines the self esteem of children with specific speech and language impairment. A sample of 69 children were first identified in Year 3. The present study focuses on their self esteem as measured by the Self Perception Profile for Children when the children were in Years 6 and 7. Data are presented for the children's self perception and for teachers' perceptions on the same dimensions. The children with SSLD had lower ratings of scholastic competence than typically developing peers, and teachers in Year 6, but not Year 7, rated the children significantly lower on these two dimensions than the children rated themselves. Comparisons between measures at Year 3, 6 and 7 revealed substantial continuities for both children's and teachers' perceptions between Year 6 and 7, and for teachers from Year 3 to Years 6 and 7. The results are interpreted with reference to theories of self esteem and the educational needs of children with SSLD.

This study was supported by a grant to Professor Julie Dockrell and Professor Geoff Lindsay from the Gatsby Charitable Trust. 


\section{SELF ESTEEM OF CHILDREN WITH SPECIFIC SPEECH AND LANGUAGE DIFFICULTIES}

\section{Geoff Lindsay, Julie Dockrell, Becky Letchford and Clare Mackie}

Children with language impairment not only experience difficulties in communication, evidence is accumulating that they are also likely to have other significant problems. This evidence is most evident in the link between language impairment and literacy (Beitchman, et al, 1996; Botting, et al, 1998; Dockrell and Lindsay, 1998; Stothard, et al, 1998). Evidence is now indicating the association between oral language problems and social/emotional/behavioural development. This has been reported by practitioners when describing the problems experienced by children with specific speech and language difficulties (SSLD) (Dockrell, et al, 1997), and also when identifying the range of difficulties present in individual children whom they have identified with SSLD (Dockrell and Lindsay, 2000; Botting and Conti-Ramsden (2000).

Evidence on the association between language impairment and social/emotional/behavioural development also comes from clinic samples. Levy, et al, (1996) report a strong relationship between attention deficit hyperactivity disorder (ADHD) with both speech and reading difficulties. Cohen, et al, (1998) report on a study of 380 children aged $7-14$ years referred for child psychiatric services with identified and unsuspected language impairment. They found greater deficits in social cognitive processing among those with language impairment than those whose language was developing normally.

A study by Lindsay and Dockrell (2000) of 69 children with SSLD also found a higher prevalence of behaviour difficulties than would be expected in a typically developing group of children of the same age (7-8 years). Using the Strengths and Difficulties Questionnaire (Goodman 1994, 1997; Yude, et al, 1998) teachers rated $44.8 \%$ of the sample having problems with hyperactivity and $27.1 \%$ having peer problems, against the expected $10 \%$ of the population in each case. This study also 
found that parents reported similar levels of difficulty for hyperactivity (44.6\%) but parents were more likely to report peer problems (46.2\%) and conduct problems (36.4).

In addition to behaviour problems, there has also been recent interest in children's self perceptions. There is a substantial body of research that has investigated this domain among both typically developing children and those with a range of difficulties. This field concerns the set of attitudes and beliefs that an individual holds towards the self (Coopersmith, 1967). To some extent this is influenced by the distance between the self-image and the person's ideal self, that is between what the person thinks they themselves are like and what they would wish to be. Harter (1999) argues that self esteem is influenced in interactions: others' behaviour affects the child's self perceptions, with negative feedback or rejection presenting a risk of low self esteem.

Studies have also indicated that it is necessary and useful to distinguish different elements of self-image as well as considering a global self-esteem or self-worth measure (Harter, 1989). Indeed the earlier interpretation of self concept as unidimensional has been superseded by a consensus on multi-dimensional models of the self (Harter, 1999). These dimensions change as a child develops. Harter and Pike (1984) report that four - to - seven year old children can make reliable judgements about the following domains: cognitive competence, physical competence, social acceptance, and behavioural conduct. However, these dimensions are not fully differentiated. For example, factor analyses reveal the cognitive and physical items combine into one competence factor, while the social acceptance and behavioural conduct items combine into a second. Harter (1989) argues it is not until middle childhood that children can make meaningful and reliable judgements about the global construct of self-worth: even though they may possess a sense of self-worth, they do not have a concept that they are able to articulate such that it can be tapped in self-report measures.

Other studies have presented evidence for a relationship between self perception and performance. For example, academic performance has been found to correlate with academic self concept (Muijs, 1997). However, there is a question about the direction 
of causality. It appears that there is a reciprocal interactive relationship; that is, perceptions of perceived competence and self-worth both impact on the behaviour itself, e.g. academic performance, while success or lack of it impacts on perceptions (Marsh, 1997). Some authors have argued that causality is predominantly from achievement to self concept (Byrne, 1996).

A recent study by Muijs (1997) of 1001 children of similar age (mean age 9:5 at time 1 and 10:5 years at time 2) provides useful evidence on this issue. He found from regression analyses that school achievement at time 1 was a stronger predictor of academic self concept a year later than the other way round. A simple structural equation model supported this. The strongest predictors of school achievement from time 1 to 2 were academic achievement (time 1 to time $2 \mathrm{r}=0.79$ ) and academic selfconcept ( time 1 to time $2 \mathrm{r}=0.55$ ). However, while academic achievement at time 1 predicted academic self-concept at time 2 at $\mathrm{r}=0.26$, the path for academic selfconcept time 1 to academic achievement time 2 was only 0.11 . Hence, although academic self-concept affects academic achievement, a stronger relationship is found with academic achievement affecting academic self concept a year later, at least among this large sample of Flemish primary school children. The weight of evidence (e.g. Muijs, 1997) supports the view that while there is an influence of academic self concept on academic achievement, the more powerful relationship is the influence of academic achievement on academic self concept.

The Muijs (1997) study, and that reported here both indicate the importance of separating elements in self-concept. A number of studies have failed to find clear evidence of relationships between global self-concept measures with academic attainment in typically developing children (e.g. Wylie, 1979), while there are now a number of studies which indicate that academic achievement is linked to academic self concept. Gresham and MacMillan (1997) also conclude that students with a range of mild learning disabilities have lower academic self-concepts but not global self-concept, than typically developing peers. In particular, lowered academic self concept, but also perceptions of peer relationships have been revealed; and these have been shown to persist throughout middle childhood. 
Children with language difficulties may be considered to be at higher risk for impaired self esteem. Not only is there a known link between language difficulties and lower levels of academic attainment, but also impaired communication ability may influence perceived competence directly. For example, language difficulties may, of themselves, lead to other children having lower estimation of a child's competence. Also, a child with language difficulties is likely to have more difficulty in social interactions, resulting in reduced ability to engage in those which either demonstrate competence per se, or allow negotiation of perceptions.

Furthermore, it might be hypothesised that a similar mechanism operates for social acceptance. A child with SSLD might perceive their social skills as lower than those of typically developing peers, given their impaired communication ability. This in turn might affect the behaviour of peers towards them, so reducing in absolute terms their level of social acceptance. Hence, there are reasonable grounds for hypothesising that children with SSLD might be subject to these influences in each direction for social acceptance. Furthermore, given the association between learning difficulties and behaviour problems, a similar two-way influence might be present in this domain also. This suggests an interactive effect between these factors.

Conti-Ramsden and Adams (1995) support the latter perspective, suggesting that peer interaction between children with specific language impairment (SLI) and typically developing peers is impaired and mainly negative, with the SLI children having difficulties making their views known and influencing the other children. However, in a study of 14 children aged $8-14$ years who probably meet the criteria for primary language difficulty, McAndrew (1999) found no significant difference between the mean scores of the sample and the standardization samples for either the Coopersmith Self-Esteem Inventory (Coopersmith, 1967) or the Piers-Harris Children's Self Concept Scale (Piers, 1984). These are uni-dimensional measures producing a global self esteem estimate and there are concerns about their reliability and validity (Wylie, 1989). 
In the present paper we address self esteem in a sample of children with specific speech and language difficulties. The present paper provides information on self perceptions of the children at Years 6 and 7, when they were about 11 and 12 years of age respectively. Comparisons with their self esteem when assessed in Year 3 at about 8 years of age are also reported (Lindsay and Dockrell, 2000).

\section{Methodology}

\section{$\underline{\text { Sample }}$}

A sample of 69 children (17 girls, 52 boys) with specific speech and language difficulties was identified at Year 3 (mean age at assessment 8;3, range 7;6-8;10). The sample included 59 children from two local education authorities, identified by professionals, and 10 from residential schools for children with SSLD. The present study comprised 67 of the same children at Year 6, mean age at assessment of 10;9 (range 10;2 to $11 ; 5$ ) and 68 in Year 7, mean age as assessment 12;1 (range 11;5 to $12 ; 7)$.

In addition, two comparison samples were created in Year 6, where practical. The first was to allow the self perceptions of the SSLD sample to be compared with those of typically developing peers in the UK, to provide a more appropriate comparison than with the original standardisation sample from the United States. The second comparison sample of children, with comparable levels of special educational needs but not in the same domain of specific speech and language difficulties, was to allow an examination of a more generalised SEN effect.

For each SSLD child in mainstream a typically developing child was selected by the teacher, who was asked to choose a child from the class of the same gender, and who was in the average range with no special educational needs: $N=42$, mean age 11;4 (range 10;5 to 11;6), 29 boys, 13 girls. Teachers were also asked to select a samegender child from the class who was at the same stage of the Code of Practice, e.g. had a statement for problems other than SSLD, or at Stage 3 or 4 if that was the case for the SSLD child: $\mathrm{N}=32$, mean age 11:2 (range 10;5 to 11;8), 24 boys, 8 girls. 
Such comparisons were not always possible, e.g. they were impossible to select in special language schools, hence the smaller sample sizes for the comparison groups.

\section{Attainment of the SSLD group}

When originally assessed in Year 3, mean age 8:3, the children had significantly impaired development on a range of abilities including language and literacy (Dockrell and Lindsay, 1998). The re-assessments in Years 6 confirmed the persistence of these difficulties. The children's mean language standard scores continued to be significantly below the population mean (e.g. British Picture Vocabulary Scale: mean standard score 81.9, SD 10.8; British Ability Scales Verbal Composite mean 81.1, SD 16.2), Test of Reception of Grammar mean 81.7, SD 12.5. Attainment scores were also depressed, e.g. BAS II Word Reading mean 79.1, SD 12.8; BAS II Spelling mean 81.8, SD 15.3. Hence, on a range of language and literacy measures the SSLD sample mean was at about the $10^{\text {th }}$ centile, representing a substantial degree of impairment in each domain. The overall picture of the individual assessments therefore confirms that the sample of children identified at Year 3 continued to have substantial language and literacy difficulties in Year 6.

\section{Procedure}

The children originally completed a measure of self esteem at Year 3. In addition, teachers also completed a parallel self esteem measure, and teachers and parents completed rating scales of social-behavioural development, and were interviewed (Lindsay and Dockrell, 2000; Dockrell and Lindsay, 2001). The present study repeated this design, with self esteem measures at Year 6 and 7 for the children and for teachers.

\section{$\underline{\text { Measures }}$}

The present paper is primarily concerned with self perceptions or self-esteem. At Year 3 this was measured using the Pictorial Scale of Perceived Competence and Social Acceptance for Young Children (PSPCSA) (Harter and Pike 1984)). At Years 6 and 7 the older version, Self Perception Profile for Children (SPPC) (Harter, 1985) 
was used. Each has acceptable psychometric properties (Harter, 1982; Harter and Pike, 1984; McGuire, 1994).

The PSPCSA comprises four scales each with six items: cognitive competence, physical competence, peer acceptance, and maternal acceptance. The version for 6/7 year olds, used in the first part of the study, comprises separate report booklets for boys and girls, with comparable activities but boy or girl figures respectively. The child chooses one of two responses to a verbal statement from the researcher, and they indicate whether they are like this child a lot or a little. Hence each of the 24 items has a possible range of 1-4 and each scale a possible range of 6-24. The teacher's version excludes the maternal acceptance scale, but is otherwise identical. It is possible to compare a child's self perception with the teacher's perceptions of the child's actual behaviour.

The Self Perception Profile of Children comprises six subscales, addressing five specific domains and a global measure: scholastic competence, social acceptance, athletic competence, physical appearance, behavioural conduct, and global self-worth. Each subscale comprises six items. Children are presented with two written statements as alternatives and asked to select which is most like them. They then choose whether this statement is 'really true of me' or 'sort of true of me'. Hence, as with the PSPCSA, there is a four point scale for each item, and a possible range of 6 24 for each subscale. In each case, changes were made to the wording of the measures both to anglicise and to simplify language without altering meaning. In addition, the SPPC was read to the child by the tester to ensure the child understood and their responses were not compromised by their poor literacy skills.

A further modification was to colour code the child's answer sheet. The responses to the left hand statement were coded dark green for 'really true for me' and light green for 'sort of true for me'. By comparison, the right hand statements were coded dark and light purple. Finally, the title of the sheet was 'What I Am Like'. These changes were made to improve user-friendliness of the SPPC for children with speech and language difficulties. 
The teacher version parallels the child version, but the teacher rates their perception of actual behaviour not how the teacher thinks the child would answer. The number of items per subscale is 3 (with potential range of 3-15) and there is no global self worth scale.

The SPPC manual (Harter, 1985) does not provide a single set of standardisation data: rather, data are presented for two or three comparative samples. Consequently the largest sample was chosen as the standardisation norms against which to compare results from the present study.

\section{$\underline{\text { Results }}$}

Investigation of the distributions of the mean subscale scores for the SPPC revealed that the majority deviated significantly from a normal distribution (KolmogorovSmirnoff one sample test). Consequently non-parametric analyses were carried out apart from the comparison of the SSLD sample with the original standardisation where a t-test was used, the non-parametric equivalent (Mann-Whitney test) not being practical as only means and standard deviations were available for the standardisation, not raw scores. To investigate whether the use of a parametric test in this case was likely to lead to substantially different results, t-tests were also carried out to duplicate the Mann-Whitney analyses presented below. In all cases, the results were essentially the same with respect to levels of significance. Consequently, the use of the parametric t-test for the comparison with the standardisation was considered acceptable.

\section{Comparison with standardisation samples}

Table 1 presents the mean scores and standard deviations for boys and girls separately for the SSLD sample children compared with the standardisation sample at Years 6 and 7.

\section{Table 1 here}


The children's perceptions of dimensions measured by the SPPC are all positive in that all means are above 2.5 on the 1-4 scale (see Table 1). Both boys and girls in the SSLD sample rate their scholastic competence and social acceptance lower than the standardisation sample at both Year 6 and Year 7. This is also the case for athletic competence for the boys at each age, while the SSLD sample girls rate themselves higher than the standardisation for physical appearance, behavioural conduct and global self worth at both ages. However, the only mean difference to reach statistical significance was for scholastic competence for Year 6 boys $(p<.05)$.

There are indications of an age effect in the SSLD sample, with the girls consistently rating themselves higher at Year 6 than Year 7. This parallels an age effect reported by Harter (1985) for the standardisation sample, where there were significant decreases between these ages for both girls and boys for scholastic competence and global self worth. However, no consistent age effect was found for boys in the SSLD sample.

Further analyses were undertaken comparing the Year 7 SSLD sample with the two comparison samples: with the typically developing children alone, using the MannWhitney test, and all three samples together, using a Kruskall-Wallis one-way analysis of variance for independent groups. Comparison of the Year 7 SSLD sample with the matched typically developing children revealed no significant differences except on scholastic competence $(\mathrm{U}=974.5(\mathrm{z}=2.23), \mathrm{p}=0.026)$ and social acceptance $(\mathrm{U}=711(\mathrm{z}=3.645), \mathrm{p}<0.001)$ : in both cases typically developing children rated themselves more positively.

A similar finding was derived from the Kruskall-Wallis one-way analysis of variance where for scholastic achievement the SSLD group had a lower mean score than that of the typical children, but the SEN comparisons had the lowest score of the three $\left(x^{2}=\right.$ 14.833 , df $2, \mathrm{p}<.001$ ) indicating the poorest perception of scholastic achievement. A comparable pattern was found for behavioural conduct $\left(x^{2}=6.686\right.$, df $\left.2, \mathrm{p}=.035\right)$ while for social acceptance it was the SSLD group which rated themselves lowest, $\left(\chi^{2}=12.832\right.$, df $\left.2, \mathrm{p}=.002\right)$. 
Hence the evidence from two comparisons, with the original standardisation and with typically developing same gender peers in the same classes, suggests that children with SSLD have poorer self perceptions with respect to scholastic achievement and peer acceptance. In addition, they have poorer perceptions of social acceptance than children with other special educational needs of similar severity.

Gender There were no significant gender differences at either Year 6 or Year $7(\mathrm{p}>$ $.05)$ other than for behavioural conduct for Year 6 only, where boys rated themselves significantly worse than did the girls (Mann-Whitney U $171(\mathrm{z}=3.25), \mathrm{p}<.001)$. This replicates the standardisation finding. However, in the standardisation sample boys also had more positive self perceptions than girls of athletic competence, physical appearance and global self worth, whereas in the SSLD sample there were no significant differences. Given the general lack of gender differences, subsequent analyses will be presented for the total sample.

\section{Inter-relationship of subscale scores}

Table 2 presents the correlations between the subscale of the SPPC for both Year 6 and Year 7. Spearman's rho was used for all correlation analyses. At both times there is a high degree of inter-correlation of subscales with 11 out of 15 correlations significant at Year 6, and 10 at Year 7. In each case there is a significant relationship at both Year 6 and Year 7 between the scholastic achievement subscale and athletic competence $(r=.47, p<.001$ at Year $6 ; \mathrm{r}=.49, \mathrm{p}<.001$ at Year 7$)$, behavioural conduct $(\mathrm{r}=.31, \mathrm{p}=.013 ; \mathrm{r}=.27, \mathrm{p}=.032)$ and global self worth $(\mathrm{r}=.42, \mathrm{p}=.001 ; \mathrm{r}$ $=.35, \mathrm{p}=.005)$. Scholastic achievement was also significantly correlated with social acceptance at Year $6(\mathrm{r}=.27, \mathrm{p}=.031)$ but not at Year $7(\mathrm{r}=.12, \mathrm{p}=.357)$. Conversely, scholastic competence was correlated significantly with physical appearance at Year $7(\mathrm{r}=.29, \mathrm{p}=.021)$ but failed to reach significance at Year $6(\mathrm{r}=$ $.24, \mathrm{p}=.058)$.

Inspection of Table 2 reveals that social acceptance was also correlated at both Year 6 and 7 with athletic competence $(\mathrm{r}=.50, \mathrm{p}<.001 ; \mathrm{r}=.34, \mathrm{p}=.007)$, physical 
appearance $(\mathrm{r}=.33, \mathrm{p}=.009)$ and global self worth $(\mathrm{r}=.46, \mathrm{p}<.001 ; \mathrm{r}=.34, \mathrm{p}=$ $.007)$.

A further analysis of the SPPC completed by the typical comparison group in Year 7 $(n=39-41)$ revealed a similar pattern in general. For example, there was a significant relationship between scholastic competence and athletic competence $(\mathrm{r}=.32, \mathrm{p}=$ $.044)$, behavioural conduct $(\mathrm{r}=.50, \mathrm{p}<.001)$ and global self worth $(\mathrm{r}=.58, \mathrm{p}<.001)$, but no significant relationship with social acceptance $(\mathrm{r}=.14, \mathrm{p}=.382)$. The correlation with physical appearance was similar, but owing to the smaller sample size failed to reach significance $(r=.27, \mathrm{p}=.094)$. However, unlike the SSLD sample, there was no significant correlation $(\mathrm{p}>.05)$ between social acceptance and any other subscale.

\section{Table 2 here}

\section{Comparison of children's and teachers' perspectives}

Comparisons of teacher and child ratings are presented in Table 3 for the SSLD sample in Year 6 and Year 7. Teachers gave significantly lower scores on scholastic competence, social acceptance and athletic competence at Year 6 only indicating they rated the children as less adequate than the children rated themselves. At Year 7 only behavioural conduct was significantly different, with teachers rating the children better behaved than the children rated themselves. Also, in general, the correlations between teacher and child ratings were non-significant $(p>.05)$ except for athletic competence $(\mathrm{r}=.41, \mathrm{p}=.002)$ and behavioural conduct $(\mathrm{r}=.31, \mathrm{p}=.019)$

A methodological issue also worthy of note was the reluctance of teachers to complete the physical appearance scale of the PSSC, resulting in just 40-42 teachers completing the three items compared with 54-58 for other items. Comments from the teachers indicated that this reflected their discomfort at commenting on the child's physical appearance, as required by these items. Consequently, there is a question about the validity of this subscale from a UK teacher cohort. 


\section{Table 3 here}

\section{The Stability of Self Perceptions}

The stability of self perceptions is indicated by Table 4 where the scores for the SSLD sample are compared at Years 6 and 7. All subscales for the children's self perceptions show high levels of stability which are highly significant $(p<.01)$ in all cases with scholastic competence showing particularly high stability $(\mathrm{r}=.58, \mathrm{p}<$ $.001)$. The teachers' ratings show a similar pattern, except for physical appearance. However, as noted above, a substantial minority of teachers declined to complete items on this scale, and the sample size for the correlation analysis was just 34, compared with 43-51 for the other scales.

\section{Table 4 here}

Evidence on longer term stability is provided in Table 5. The ratings recorded by the children at Year 3 on the Pictorial Scale of Perceived Competence and Social Acceptance for Young Children (PSPCSA) are compared with their ratings at Year 6 and 7 on the SPPC for the three domains with comparable scales: cognitive competence $\mathrm{v}$ scholastic achievement; peer acceptance $\mathrm{v}$ social acceptance; and physical competence $\mathrm{v}$ athletic competence. Information is also available for teachers' judgements at both Years 6 and 7.

\section{Table 5 here}

Table 5 indicates that there is low stability for children's self perceptions from Year 3 to Years 6 and 7, and that only cognitive competence/scholastic achievement produces a significant correlation, and only from Year 3 to Year $7(r=.29, p=.02)$. However, the correlations between teacher judgements at Year 3 compared with both Years 6 and 7 are all significant, with a very high correlation for cognitive competence/scholastic achievement at Year $6(\mathrm{r}=.76, \mathrm{p}<.001)$. These high levels of 
stability are particularly noteworthy as different teachers rated the children on each occasion.

\section{$\underline{\text { Discussion }}$}

The present study of this sample of children with specific speech and language difficulties (SSLD) at Years 6 and 7, confirms patterns revealed when they were in Year 3. The children's mean scores on all subscales of the Self Perception Profile for Children (SPPC) at both Years 6 and 7 were all above the scale mean of 2.5, indicating relatively positive self perceptions as defined by the structure of the scale. However, relative both to the standardisation sample, and to the typical comparison group in the present study, the SSLD group at Year 6 had lower ratings of their scholastic competence and social acceptance; indeed their perceived social acceptance was lower than that of the SEN comparison group. This finding differs from that reported by McAndrew (1999) who found no significant differences between the language-disorder group and the standardisation samples for her measures of self esteem. Furthermore, the teachers' views of the children's status at Year 6 on these two variables as well as their athletic competence, indicated even lower levels of performance. This also replicates the finding at Year 3 for comparable scales on the Pictorial Scale of Perceived Competence and Social Acceptance of Young Children (PSPCSA). On the other hand, the perceptions of global self worth of these children with SSLD do not differ from either the standardisation sample or the typically developing comparison group. This replicates findings with a range of children with mild learning disabilities reported by Gresham and MacMillan (1997).

Unlike the standardisation sample, the present SSLD sample showed a lack of gender differences at Years 6 and 7. In the former, boys tended to present more positive self perceptions on most subscales. Only with respect to behavioural conduct is there a similar finding across the two samples, at Year 6 only, with girls seeing themselves as better behaved in both. This lack of gender differences was also found at Year 3 on the PSPCSA when the only significant findings were for maternal acceptance, with girls rating themselves higher. 
The reason for the lack of gender difference in the present sample is not immediately clear. It may be that the difficulties experienced by the children are so marked they serve to rule out any gender differences. Alternatively the language and literacy assessments indicated that the girls were performing significantly worse than the boys. This reduced level of performance in the girls may serve to reduce further their views of themselves and their attributes.

There are patterns of stability reflected in these results, which are evidenced by the analyses of the inter-relationship of subscales across Year 6 and 7 (see Table 2) and the correlations between the children's ratings of themselves between years 6 and 7 (see Table 4). Correlations between children's ratings of their cognitive/scholastic competence/scholastic achievement are particularly stable with significant correlation between Year 3 and Year 7 as well as Year 6 and 7. There is also evidence from teachers' perceptions of the children's behaviour on the same domains having stability from Year 3 to Years 6 and 7; cognitive competence/scholastic achievement is particularly highly correlated at Year $6(\mathrm{r}=0.76)$, and there is a comparable pattern of teachers' ratings being lower than children's self-perceptions at Year 3 (PSPCSA) and Year 6 (SPPC), as shown in Table 3.

The present study at Year 6 and 7, therefore, has replicated findings on the same sample when in Year 3. These children with SSLD not only have impaired communication ability, and reduced levels of achievement, they also rate themselves lower with respect to their academic ability and achievement, and their relationships with peers. Furthermore, these patterns have been formed to persist over the period from Year 3 to Year 7, indicating a substantial degree of stability.

\section{$\underline{\text { Conclusions }}$}

The present study has demonstrated that children with specific speech and language difficulties at the ages of about 10 to 11 years not only have educational difficulties, they also have lower estimations of their academic ability and their competence in peer relationships. Furthermore, these characteristics are persistent, with evidence of continuities from Year 3 to Years 6 and 7 (from about 8 to 12 years). 
The study contributes both to the general literature on self concept, supporting evidence which demonstrates the need to be analytic and investigate specific domains of self perception, not just global self concept. It also extends the research on children with a variety of learning difficulties to those with specific speech and language difficulties.

With respect to action, the weight of evidence favours the interpretation that academic self concept is primarily determined by academic achievement rather than the opposite way round (e.g. Muijs, 1997). This poses a challenge to professionals working with children with SSLD, given their significant educational difficulties. However, despite the substantial under achievement of these children, their academic self perception is still positive albeit significantly lower than that of typically developing children. This suggests that either these children are denying, in relative terms, their difficulties, the 'aggrandisement of self' hypothesis (Edgerton and Sabagh, 1962), or that the experiences the children have are sufficiently supportive in relative terms to ameliorate the negative impact of their difficulties. For example, they may produce their judgements on the basis of progress rather than absolute levels of achievement.

There are also implications with respect to perceived social acceptance. If social acceptance is related, at least in part, to success at school at this stage of childhood, then lower academic achievements are likely to affect perceptions of social acceptance also. This effect may be ameliorated by strengths in other domains, and the correlation between social acceptance and athletic competence suggests that the latter may act in this way. Indeed, interviews with teachers when the children were in Year 3 suggested this was operating in some cases (Dockrell and Lindsay, 2001). However, given that teachers rate the children's social acceptance lower than the children rate themselves, there is a need not only to improve children's perceptions but their actual social skills also.

The present study provides further evidence for the multiple and aggregating effects of difficulties experienced by children with SSLD. In addition to their 
communication difficulties, they have educational problems, and are also more likely to have problems with behaviour (Lindsay and Dockrell, 2000) and self esteem. The implications are that intervention must recognise these multiple and interacting needs. 


\section{$\underline{\text { References }}$}

Beitchman, J.M., Wilson, B., Brownlie, E.B., Walters, H., \& Lancee, W: 1996. Longterm consistency in speech/language profiles. 1. Developmental and academic outcomes. Journal of American Academy of Child and Adolescent Psychiatry, 35, 804-814

Botting, N. \& Conti-Ramsden, G: 2000. Social and behavioural difficulties in children with language impairment. Child Language Teaching and Therapy $16,105-120$

Botting, N., Crutchley, A. \& Conti-Ramsden, G.:1998 Educational transitions of 7year-old children with SLI in language units: a longitudinal study. International Journal of Language and Communication Disorders, 33, 177197.

Byrne, D: 1996 Measuring self-concept across the life-span: Issues and instrumentation. Washington, D.C.: American Psychological Association.

Cohen, N.J., Barwick, M.A., Horodezky, N.B., Vallance, D.D. \& Im, N: 1998. Language, achievement and cognitive processing in psychiatrically disturbed children with previously identified and unsuspected language impairments. Journal of Child Psychology and Psychiatry, 39, 865-877.

Conti-Ramsden, G. and Adams, C: 1995 Transitions from the clinic to the school: The changing picture of specific language impaired children from pre-school to school age. Journal of Speech and Language Studies. 5, 1-11.

Coopersmith, S: 1981 The self-esteem inventories (SEI manual) Palo Alto California: Consulting Psychologist Press.

Coopersmith, S: 1967 The antecedents of self-esteem. Palo Alto, California: Consulting Psychologists Press.

Dockrell, J. \& Lindsay, G: 1998. The ways in which speech and language difficulties impact on children's access to the curriculum. Child Language Teaching and Therapy. 14, 117-133.

Dockrell, J. and Lindsay, G: 2001 Children with specific speech and language difficulties: the teachers' perspectives. Oxford Review of Education. 27, (3), 369-394. 
Dockrell, J., George, R., Lindsay, G., and Roux, J: 1997 Problems in the identification and assessment of children with specific speech and language difficulties, Educational Psychology in Practice. 12, 29-38.

Goodman, R: 1994. A modified version of the Rutter parent questionnaire including items on children's strengths. Journal of Child Psychology and Psychiatry. 35, 1483-1494.

Goodman, R: 1997 The strengths and difficulties questionnaire: a research note. Journal of Child Psychology and Psychiatry. 38, 581-586.

Gresham, F.M., MacMillan, D.L: 1997 Social competence and affective characteristics of students with mild disabilities. Review of Educational Research. 67 (4), 377-415.

Harter, S: 1999 The construction of self: A developmental perspective. London: The Guilford Press.

Harter, S: 1985 Manual for the self-perception profile for children. Denver, Co.: University of Denver

Harter, S. \& Pike, R: 1984. The pictorial perceived competence scale for young children. Child Development. 55, 1969-1982.

Harter, S: 1989. Causes, correlates and the functional role of global self-worth: a lifespan perspective, In J. Kolligian and R. Sternberg (eds) Perceptions of competence and incompetence across the lifespan. (pp 67-97). New Haven, CT : Yale University Press.

Levy, F., Hay, D., McClaughlin, M., Wood, C., \& Walman, I: 1996. Twin-sibling differences in parental reports of ADHD, speech, reading, and behaviour problems. Journal of Child Psychology and Psychiatry. 37(5), 569-578.

Lindsay, G. and Dockrell, J: 2000 The behaviour and self-esteem of children with specific speech and language difficulties, British Journal of Educational Psychology. 70, 583-601.

Marsh, H., Craven, R. \& Debus, R: 1991. Self-Concepts of young children 5 to 8 years of age: measurement and multidimensional structure. Journal of Educational Psychology. 83, 377-392.

McAndrew, E: 1999: The relationship between self-esteem and language disordered children. Child Language Teaching and Therapy. 15 (3), 219-232. 
McGuire, S: 1994 Measuring self-concept in children, Association of Child Psychology and Psychiatry Review. 16 (2), 83-87.

Muijs, R.D: 1997 Symposium: Self-perception and Performance. Predictors of academic achievement and academic self-concept: a longitudinal perspective. British Journal of Educational Psychology. 67, 263-277.

Piers, E.V: 1984 Piers-Harris children's self concept scale: Revised manual. Los Angeles, CA: Western Psychology Services.

Stothard, S., Snowling, M., Bishop, D.V.M., Chipchase, B. and Kaplan, C: 1998. Language Impaired Preschoolers: A follow-up into adolescence. Journal of Speech, Language and Hearing Research. 41, 407-418.

Wylie, R.C: 1979 The Self-concept Volume 2: Theory and research on selected topics. Lincoln: University of Nebrasko Press.

Wylie, R.C: 1989 Measures of Self-concept. Lincoln: University of Nebraska Press.

Yude, C., Goodman, R. \& McConachie, H: 1998. Peer problems of children with hemiplegia in mainstream primary schools. Journal of Child Psychology and Psychiatry. 39, 533-541. 
Table 1

Means (standard deviations) of children with SSLD at Year 6 and 7 on the Self Perception Profile for Children compared with the standardisation

\begin{tabular}{|c|c|c|c|c|}
\hline & \multicolumn{2}{|c|}{ Boys } & \multicolumn{2}{|c|}{ Girls } \\
\hline Year 6 & SSLD & Standardisation & SSLD & Standardisation \\
\hline Scholastic achievement & $2.57(.78)$ & $2.94(.62)$ & $2.72(.78)$ & $2.94(.64)$ \\
\hline Social acceptance & $2.87(.78)$ & $3.06(.63)$ & $2.91(.76)$ & $2.98(.69)$ \\
\hline Athletic competence & $2.79(.69)$ & $3.15(.61)$ & $2.82(1.04)$ & $2.80(.69)$ \\
\hline Physical appearance & $2.98(.59)$ & $2.98(.68)$ & $3.00(.63)$ & $2.68(.75)$ \\
\hline Behavioural conduct & $2.86(.74)$ & $2.92(.60)$ & $3.50(.57)$ & $3.06(.56)$ \\
\hline Global self worth & $3.06(.71)$ & $3.20(.61)$ & $3.38(.55)$ & $3.10(.65)$ \\
\hline $\mathbf{N}=$ & 48 & & 16 & \\
\hline Year 7 & SSLD & Standardisation & SSLD & Standardisation \\
\hline Scholastic achievement & $2.57(.66)$ & $2.78(.55)$ & $2.57(.94)$ & $2.80(.61)$ \\
\hline Social acceptance & $2.79(.65)$ & $3.00(.61)$ & $2.81(.61)$ & $2.96(.57)$ \\
\hline Athletic competence & $2.96(.61)$ & $3.11(.62)$ & $2.46(.88)$ & $2.54(.78)$ \\
\hline Physical appearance & $3.06(.54)$ & $2.93(.62)$ & $2.67(.92)$ & $2.50(.68)$ \\
\hline Behavioural conduct & $2.97(.64)$ & $2.83(.51)$ & $3.29(.59)$ & $2.96(.62)$ \\
\hline Global self worth & $3.10(.48)$ & $3.20(.52)$ & $3.18(.73)$ & $2.97(.62)$ \\
\hline $\mathbf{N}=$ & 49 & & 15 & \\
\hline
\end{tabular}


Table 2 The Inter-relationship of the Subscales of the Self Perception

Profile for Children at Years 6 and 7

\begin{tabular}{|c|c|c|c|c|c|}
\hline Year 6 & $\begin{array}{c}\text { Scholastic } \\
\text { Achievement }\end{array}$ & $\begin{array}{c}\text { Social } \\
\text { Acceptance }\end{array}$ & $\begin{array}{c}\text { Athletic } \\
\text { Competence } \\
\end{array}$ & $\begin{array}{c}\text { Physical } \\
\text { Appearance }\end{array}$ & $\begin{array}{c}\text { Behavioural } \\
\text { conduct }\end{array}$ \\
\hline Social acceptance &, $27^{\mathrm{X}}$ & & & & \\
\hline Athletic competence & $.47^{\mathrm{Xxx}}$ & $.50^{\mathrm{Xxx}}$ & & & \\
\hline Physical appearance & .24 & $.33^{\mathrm{xx}}$ & $.38^{x x}$ & & \\
\hline Behavioural conduct & $.31^{x}$ & .20 & .17 & $.29^{x}$ & \\
\hline Global self worth & $.42^{\mathrm{XX}}$ & $.46^{\mathrm{Xx}}$ & .24 & $.49^{\mathrm{Xxx}}$ & $.45^{\mathrm{xxx}}$ \\
\hline \multicolumn{6}{|l|}{$N=60-63$} \\
\hline \multicolumn{6}{|l|}{ Year 7} \\
\hline Social acceptance & .12 & & & & \\
\hline Athletic competence & $.49^{\mathrm{xxx}}$ & $.34^{\mathrm{xx}}$ & & & \\
\hline Physical appearance & $.29^{x}$ & $.34^{\mathrm{xx}}$ & $.45^{\mathrm{xxx}}$ & & \\
\hline Behavioural conduct & $.27^{\mathrm{x}}$ & .16 & .24 & .18 & \\
\hline Global self worth & $.35^{\mathrm{xx}}$ & $.34^{\mathrm{Xx}}$ & $.35^{x}$ & $.47^{\mathrm{XXx}}$ & .13 \\
\hline$N=60-64$ & & & & & \\
\hline
\end{tabular}

${ }^{\mathrm{x}} \mathrm{p}<.05,{ }^{\mathrm{xx}} \mathrm{p}<.01,{ }^{\mathrm{xvv}} \mathrm{p}<.001$ 
Table 3 Comparison of teachers' v children's rating on the Self Perception Profile for children, Years 6 and 7

\begin{tabular}{|l|c|c|c|c|c|c|c|}
\hline & \multicolumn{2}{|c|}{ Teacher } & \multicolumn{2}{c|}{ Child } & & \\
\hline Year 6 & Mean & SD & Mean & SD & N & Z & P \\
\hline Scholastic achievement & 1.97 & .78 & 2.60 & .77 & 58 & -4.180 & $<.001$ \\
\hline Social acceptance & 2.52 & .87 & 2.85 & .78 & 56 & -2.236 & .025 \\
\hline Athletic competence & 2.56 & .79 & 2.76 & .76 & 57 & -3.788 & $<.001$ \\
\hline Physical appearance & 3.03 & .78 & 2.97 & .60 & 52 & -0.573 & .567 \\
\hline Behavioural conduct & 3.03 & .82 & 3.05 & .74 & 57 & 0 & 1.0 \\
\hline Year 7 & & & & & & & \multicolumn{2}{|c|}{. } \\
\hline Scholastic achievement & 2.55 & .79 & 2.61 & .75 & 53 & -.513 & .608 \\
\hline Social acceptance & 2.71 & .81 & 2.80 & .68 & 49 & -.798 & .425 \\
\hline Athletic competence & 2.67 & .76 & 2.90 & .74 & 45 & -1.491 & .136 \\
\hline Physical appearance & 3.17 & .68 & 2.88 & .81 & 35 & 1.560 & .119 \\
\hline Behavioural conduct & 3.31 & .71 & 3.13 & 56 & 54 & 2.105 & .035 \\
\hline
\end{tabular}


Table 4 Comparison of Self Perception Profile for Children at Years 6 and 7

\begin{tabular}{|c|c|c|}
\hline SPPC Subscale & children & teachers \\
\hline Scholastic achievement & $.58^{\mathrm{xxx}}$ & $.49 * * *$ \\
\hline Social acceptance & $.49^{\times x}$ & $.52 * * *$ \\
\hline Athletic competence & $.54^{\mathrm{xx}}$ & $.43 * *$ \\
\hline Physical appearance & $.36^{x x}$ & .27 \\
\hline Behavioural conduct & $.43^{\times \times x}$ & $.50 * * *$ \\
\hline Global self worth & $.51^{\mathrm{xxx}}$ & N/a \\
\hline
\end{tabular}

$\mathrm{n}=\mathbf{5 8 - 6 9}$

${ }^{\mathrm{x}} \mathbf{P}<.01,{ }^{\mathrm{xxx},}, \mathbf{p}<.001$ 
Table 5 Children's and Teachers' ratings of competence and acceptance at $\underline{\text { Year 3, compared with Years } 6 \text { and } 7}$

\begin{tabular}{|c|c|c|}
\hline Children & Year 6 & Year 7 \\
\hline Cognitive competence v scholastic achievement & .21 & $.29^{x}$ \\
\hline Peer acceptance $v$ social acceptance & .14 & .07 \\
\hline Physical competence $v$ athletic competence & .05 & .05 \\
\hline $\mathbf{n}=$ & $60-62$ & $60-62$ \\
\hline \multicolumn{3}{|l|}{ Teachers } \\
\hline Cognitive competence $v$ scholastic achievement & $.76^{\mathrm{xxx}}$ &. $.44^{x \times x}$ \\
\hline Peer acceptance v social acceptance & $.37^{\mathrm{xx}}$ & $.53^{x \times x}$ \\
\hline Physical competence $v$ athletic competence & $.47^{\mathrm{XXX}}$ & $.48^{x \times x}$ \\
\hline $\mathbf{n}=$ & $60-63$ & 43-48 \\
\hline
\end{tabular}

${ }^{\mathrm{x}} \mathrm{p}<.05,{ }^{\mathrm{xx}} \mathrm{p}<0.01,{ }^{\mathrm{xxx}} \mathrm{p}<.001$ 